\title{
Determination of Activity Concentration of Natural Radionuclides and Radiation Hazards' Assessment of Building Materials in High Background Radiation Areas of Homa and Ruri, Kenya
}

\author{
Willis Otieno Gor Odongo ${ }^{(D)},{ }^{1,2}$ Margaret Chege ${ }^{(D)},{ }^{1}$ Nadir Hashim ${ }^{(D)},{ }^{1}$ Shinji Tokonami $\left(\mathbb{D},{ }^{3}\right.$ \\ Kranrod Chutima $\left(\mathbb{D},{ }^{3}\right.$ and Charles Rotich $\mathbb{D}^{1}$ \\ ${ }^{1}$ Department of Physics, Kenyatta University, P.O. Box 43844, Nairobi, Kenya \\ ${ }^{2}$ Department of Physics, Kisii University, P.O. Box 408, Kisii, Kenya \\ ${ }^{3}$ Institute of Radiation Emergency Medicine, Hirosaki University, Hirosaki, Aomori, Japan
}

Correspondence should be addressed to Willis Otieno Gor Odongo; willisgor85@gmail.com

Received 27 April 2021; Revised 16 November 2021; Accepted 26 November 2021; Published 14 December 2021

Academic Editor: Karoly Nemeth

Copyright (c) 2021 Willis Otieno Gor Odongo et al. This is an open access article distributed under the Creative Commons Attribution License, which permits unrestricted use, distribution, and reproduction in any medium, provided the original work is properly cited.

\begin{abstract}
The areas around Homa and Ruri hills in Homa Bay County in Kenya are associated with high background radiation levels. The activity concentration of the natural radionuclides $\left({ }^{226} \mathrm{Ra},{ }^{232} \mathrm{Th}\right.$, and $\left.{ }^{40} \mathrm{~K}\right)$ in earthen building materials used in the areas of Homa and Ruri hills has been measured using a $\mathrm{NaI}(\mathrm{Tl})$ detector in this work. The measured values of radioactivity concentrations are used to estimate the associated radiological risk. The earthen building material samples from Ruri registered relatively high ${ }^{232} \mathrm{Th}$ concentration values averaging $1094 \pm 55 \mathrm{~Bq} / \mathrm{kg}$, nearly three times those of the samples from Homa. ${ }^{226}$ Ra level was not significantly different in both regions with Homa reporting $129 \pm 10 \mathrm{~Bq} / \mathrm{kg}$ and Ruri $111 \pm 6 \mathrm{~Bq} / \mathrm{kg} .{ }^{40} \mathrm{~K}$ was however higher in the samples from Homa by an approximate factor of 2 relative to those from Ruri where the activity concentration was $489 \pm 24 \mathrm{~Bq} / \mathrm{kg}$. The radium equivalents for ${ }^{226} \mathrm{Ra}$, ${ }^{232} \mathrm{Th}$, and ${ }^{40} \mathrm{~K}$ in the samples from Ruri were $111 \pm 9,1564 \pm 125$, and $38 \pm 3 \mathrm{~Bq} / \mathrm{kg}$, while in Homa, the values were $129 \pm 10,570 \pm 46$, and $69 \pm 5 \mathrm{~Bq} / \mathrm{kg}$, respectively. The calculated value of total radium equivalent in Ruri was $1713 \pm 137 \mathrm{~Bq} / \mathrm{kg}$ which was two times higher than that of Homa. ${ }^{232}$ Th contributed about $74 \%$ and $91 \%$ to the total radium equivalent in Homa and Ruri, respectively; thus, it was the one with the largest contribution to radiation exposure in both regions. The average indoor annual effective dose rates were $1.74 \pm 0.14$ and $3.78 \pm 0.30 \mathrm{mSv} / \mathrm{y}$ in Homa and Ruri, respectively, both of which were above the recommended safety limit of $1 \mathrm{mSv} / \mathrm{y}$.
\end{abstract}

\section{Introduction}

Natural radiation in the environment contributes approximately eighty percent of the total radiation exposure to the general public. The major categories of natural exposure include inhalation of radon and thoron, external exposure from $\left({ }^{226} \mathrm{Ra},{ }^{232} \mathrm{Th}\right.$, and $\left.{ }^{40} \mathrm{~K}\right)$, cosmic radiation, and ingestion of food and water [1]. The major natural contributors to external exposure are the primordial radionuclides ${ }^{226} \mathrm{Ra}$, ${ }^{232} \mathrm{Th}$, and ${ }^{40} \mathrm{~K}$ which are not uniformly distributed in the environment but occur in varying quantities in rock and soil as characterized by the geology of a region [2]. The average worldwide dose rate as a result of these terrestrial radionuclides is about $60 \mathrm{nGy}^{-1}$ for areas with normal background. Therefore, it is important to determine their levels in soil and rocks, as well as their individual contributions to the total radiation dose for purposes of radiation protection and management [3]. High background radiation areas (HBRAs) are characterized by abnormally high levels of background radiation; they are distributed throughout the world, e.g., Yangjiang, China; Guarapari, Brazil; Ramsar, Iran; and Kerala, India $[4,5,6,7]$. In Kenya, some of the HBRAs include Mrima hill in the coastal part of Kenya and Homa and Ruri in southwestern Kenya $[8,9,10]$. Studies carried out, for instance, in high background radiation areas of Ramsar, Iran [11], and Mrima hill, Kenya, have shown 
that building materials contribute significantly to indoor radiation exposure. Homa and Ruri are both experiencing increased growth in human settlement with readily available soil being used as a building material. Therefore, there exist a potential radiation risk indoors from the soil used as the building material in these regions and the fact that people generally spend more time indoors. Despite this apparent risk, there are no data on radiation exposure as a result of the terrestrial radionuclides inside the local earthen dwellings in Homa and Ruri which this research seeks to determine. This paper reports the activity concentration of the primordial radionuclides in the earthen building materials used in the two regions as well as the risk indices associated with them. The radionuclides responsible for the highest radiation exposure are also determined.

\section{Methodology}

2.1. Study Area. Homa and Ruri hills are located in Homa Bay County along the shores of Lake Victoria in Kenya.

Homa hill is located between latitude $0^{\circ} 30^{\prime} \mathrm{N}$ and $0^{\circ} 20^{\prime}$ $\mathrm{N}$ and longitude $33^{\circ} 26^{\prime} \mathrm{E}$ and $34^{\circ} 34^{\prime} \mathrm{E}$. This is mainly covered by a large carbonatite peninsula complex on the eastern shores of Lake Victoria with a series of cone sheets of carbonatite and breccia intrusions in the oldest rock in the Nyanzian series and ijolites [12].

Ruri hill is located at latitudes $0^{\circ} 30^{\prime} \mathrm{S}$ and $1^{\circ} 00^{\prime} \mathrm{S}$ and longitude $34^{\circ} 30^{\prime} \mathrm{E}$ and Lake Victoria shoreline. The altitudes range from about $1000 \mathrm{~m}$ to approximately $1800 \mathrm{~m}$ at the hilltop. This area is mainly covered by Precambrian metabasalt of the Nyanzian type of rocks composed of ijolites and the nepheline syenites [13]. The hill also has a ring-shaped intrusion of carbonatites of lower tertiary age and monazite and pyrochlore minerals associated with high ${ }^{232}$ Th levels [14]. Figure 1 shows the map of Homa Bay County and the two hills with the sampling points marked with the dots around each region.

2.2. Sample Collection and Its Preparation. Fifteen soil lumps were chopped off from the earthen walls of randomly selected houses in each region. In the laboratory, each lump was crushed to a fine powder before drying in an oven at a temperature of $110^{\circ} \mathrm{C}$ for a period of 24 hours. $250 \mathrm{~g}$ mass of each soil sample was then sealed in a Marinelli beaker, labelled, and stored for about 4 weeks to attain radioactive secular equilibrium between ${ }^{226} \mathrm{Ra}\left({ }^{238} \mathrm{U}\right.$ decay chain) series and ${ }^{232} \mathrm{Th}$ series and their daughters [15].

\section{Experimental Techniques}

3.1. Radionuclide Concentration Analysis Using Gamma-Ray Spectroscopy $(\mathrm{NaI}(\mathrm{Tl}))$. The gamma-ray spectrometer used in this work is composed of a $76 \mathrm{~mm} \times 76 \mathrm{~mm}$ thalliumactivated sodium iodide $(\mathrm{NaI}(\mathrm{Tl})$ ) single-crystal detector and an Oxford PCA-P multichannel analyzer which is a PCbased plugin PCI card. It consists of an $80 \mathrm{MHz}$ Wilkinson analogue-to-digital converter for spectral data acquisition. The energy calibration of the detector was done using caesium-137 at the energy peak of $662 \mathrm{keV}$ and cobalt- 60 at energy peaks of $1170 \mathrm{keV}$ and $1330 \mathrm{keV}$. The detector efficiency calibration was done using International Atomic Energy Agency (IAEA) standard-certified reference materials RGU-1, RGTh-1, and RGK-1 having the same geometry as the samples, and each was counted for a period of 30,000 seconds. ${ }^{226} \mathrm{Ra}$ and ${ }^{232} \mathrm{Th}$ activity concentrations were determined based on the ${ }^{214} \mathrm{Bi}$ gamma energy peak of $609 \mathrm{keV}$ and ${ }^{208} \mathrm{Tl}$ at the energy peak of $2615 \mathrm{keV}$, respectively, while for ${ }^{40} \mathrm{~K}$, an energy peak of $1460 \mathrm{keV}$ was used from the spectrum of the background counting. The background counts were then used for the correction of net peak area of gamma rays of the measured standard isotopes. The minimum detectable activity (MDA) for ${ }^{40} \mathrm{~K},{ }^{232} \mathrm{Th}$, and ${ }^{226} \mathrm{Ra}$ was determined as $1.4,0.196$, and $0.401 \mathrm{~Bq}$, respectively.

The activity concentration was determined by using the following equation [15]:

$$
A_{i}=\frac{N}{\gamma m n t}
$$

where $A_{i}$ is the activity concentration of radionuclide $i, N$ is the residual net counts at the peak energy of interest, $\gamma$ is the emission probability of the gamma ray of interest, $m$ is the mass of the sample in $\mathrm{kg}, n$ is the detection efficiency of the gamma ray of interest, and $t$ is the acquisition time in seconds.

3.2. Radium Equivalent Activity ( $\left.R a_{e q}\right)$. Radium equivalent activity is a single value that describes the gamma output from the terrestrial natural radionuclides as determined by the following equation [15]:

$$
\mathrm{Ra}_{\mathrm{eq}}=A_{\mathrm{Ra}}+1.429 A_{\mathrm{Th}}+0.0769 A_{\mathrm{K}},
$$

where $A_{\mathrm{Ra}}, A_{\mathrm{Th}}$, and $A_{\mathrm{K}}$ are the activity concentrations of ${ }^{226} \mathrm{Ra},{ }^{232} \mathrm{Th}$, and ${ }^{40} \mathrm{~K}$, respectively. 1.429 and 0.0769 are conversion factors for ${ }^{232} \mathrm{Th}$ and ${ }^{40} \mathrm{~K}$, respectively.

3.3. Absorbed Gamma Radiation Dose Rate (D). Absorbed gamma radiation dose rate is the dose of ionizing radiation per unit time and is dependent on the concentration of the terrestrial radionuclides in the earthen building materials. The absorbed gamma dose rate $D(\mathrm{nGy} / \mathrm{h})$ in air considered $1 \mathrm{~m}$ above the ground surface was determined using the following equation [1]:

$$
D=0.462 A_{\mathrm{Ra}}+0.604 A_{\mathrm{Th}}+0.0417 A_{\mathrm{K}},
$$

where $0.462,0.604$, and $0.0417 \mathrm{nGyh}^{-1} / \mathrm{Bqkg}^{-1}$ are dose conversion factors for ${ }^{226} \mathrm{Ra},{ }^{232} \mathrm{Th}$, and ${ }^{40} \mathrm{~K}$, respectively, and $A_{\mathrm{Ra}}, A_{\mathrm{Th}}$, and $A_{\mathrm{K}}$ are the activity concentrations of ${ }^{226} \mathrm{Ra}$, ${ }^{232} \mathrm{Th}$, and ${ }^{40} \mathrm{~K}$ in $\mathrm{Bq} / \mathrm{kg}$, respectively.

3.4. Indoor Annual Effective Absorbed Dose Rate (AEDR). Indoor annual effective absorbed dose rate is the measure of biological effect of radiation on humans inside a dwelling made of the soil. It was determined by the following equation $[1,16,17]$ : 


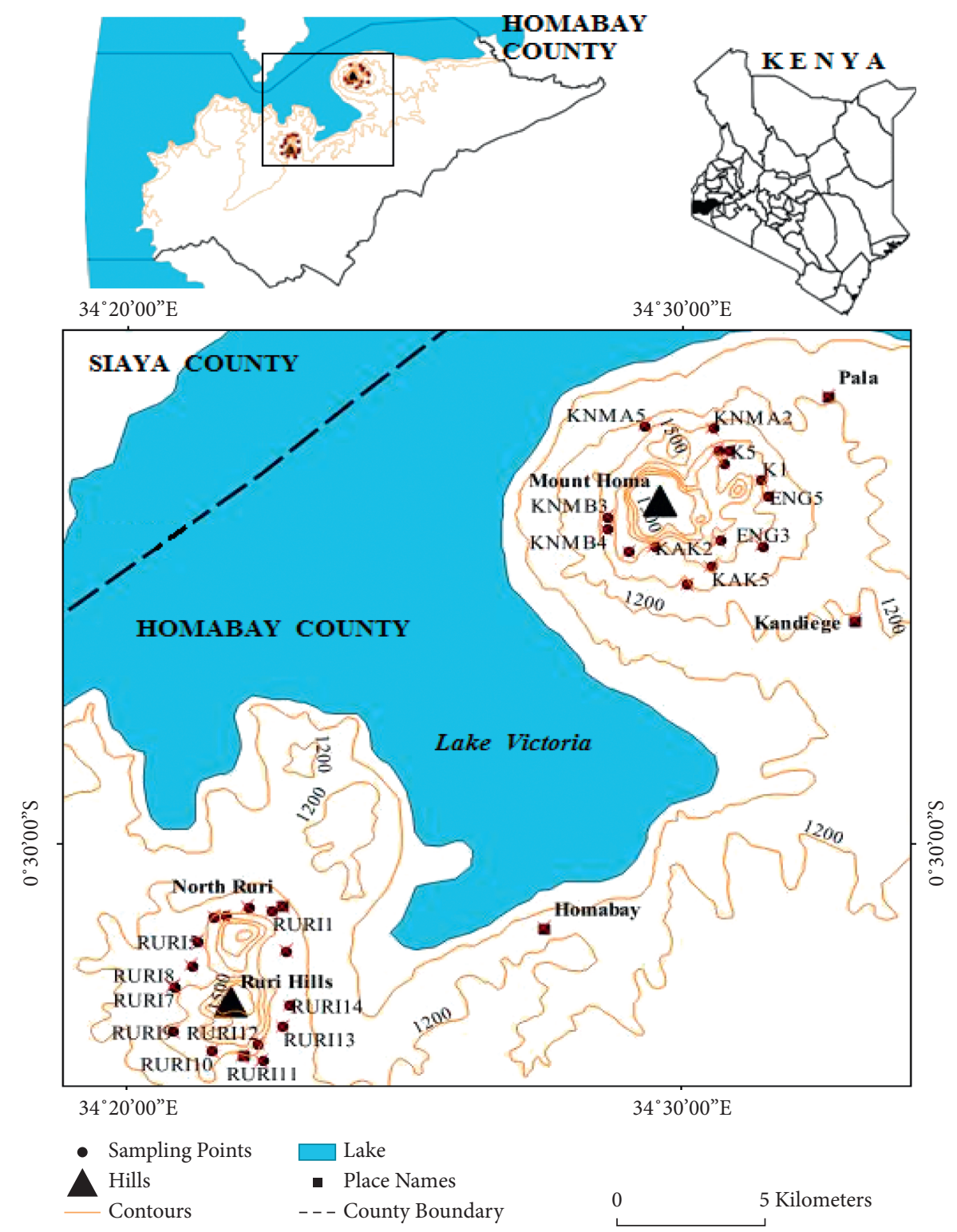

Figure 1: A map of Homa Bay County showing both Homa and Ruri hills (sample points marked with the dots around each hill).

$$
\mathrm{AEDR}=D\left(\frac{n G y}{h}\right) \times 8,760 h \times 0.6 \times 0.7\left(\frac{S v}{G y}\right),
$$

where AEDR is the indoor annual effective absorbed dose rate in $\mathrm{mSv} / \mathrm{y}, \mathrm{D}$ is the absorbed dose rate in $\mathrm{nGy} / \mathrm{h}, 8760$ is the time in hours for a whole normal year of 365 days, 0.6 is the rural Kenya indoor occupancy factor [8], and 0.7 Sv/Gy is the gamma dose conversion factor; 1.4 is a factor that accounts for the indoor environment given that gamma dose rates indoor are about 1.4 times higher than outdoors $[8,16,17]$.

\section{Results and Discussion}

The activity concentration of ${ }^{226} \mathrm{Ra},{ }^{232} \mathrm{Th}$, and ${ }^{40} \mathrm{~K}$ in Homa and Ruri is summarized in Tables 1 and 2, respectively. In both regions, the activity concentration of ${ }^{226} \mathrm{Ra}$ had no significant difference between them with average values of $129 \pm 10 \mathrm{~Bq} / \mathrm{kg}$ and $111 \pm 6 \mathrm{~Bq} / \mathrm{kg}$. respectively. The average value of ${ }^{232} \mathrm{Th}$ was approximately $60 \%$ higher in Ruri compared to Homa which had an average of $399 \pm 20 \mathrm{~Bq} / \mathrm{kg}$; this was attributed to the ring intrusion of monazite and pyrochlore minerals in Ruri associated with higher thorium concentration [13]. On the contrary, the average activity concentration of ${ }^{40} \mathrm{~K}$ was about $40 \%$ higher in Homa than Ruri which had an average of $489 \pm 24 \mathrm{~Bq} / \mathrm{kg}$, which was attributed to the alkaline igneous rocks in Homa associated with higher potassium levels [18]. Average activity concentration of ${ }^{226} \mathrm{Ra}$ was approximately 3 times higher than the world average of $35 \mathrm{~Bq} / \mathrm{kg}$ in both Homa and Ruri.

The average activity concentration of ${ }^{232} \mathrm{Th}$ was 13 and 36 times higher than the world average of $30 \mathrm{~Bq} / \mathrm{kg}$ in Homa and Ruri, respectively. The arithmetic mean of ${ }^{40} \mathrm{~K}$ was twice that of the world average of $400 \mathrm{~Bq} / \mathrm{kg}$ in Homa but was 
TABLe 1: Activity concentration of ${ }^{40} \mathrm{~K},{ }^{226} \mathrm{Ra}$, and ${ }^{232} \mathrm{Th}(\mathrm{Bq} / \mathrm{kg})$ in Homa samples.

\begin{tabular}{lccc}
\hline Sample ID & ${ }^{226} \mathrm{Ra}(\mathrm{Bq} / \mathrm{kg})$ & ${ }^{232} \mathrm{Th}(\mathrm{Bq} / \mathrm{kg})$ & \\
\hline Homa1 & $259 \pm 21$ & $598 \pm 30$ & $946 \pm 47$ \\
Homa2 & $178 \pm 14$ & $670 \pm 34$ & $1294 \pm 65$ \\
Homa3 & $67 \pm 5$ & $493 \pm 25$ & $1036 \pm 52$ \\
Homa4 & $129 \pm 10$ & $631 \pm 32$ & $1103 \pm 55$ \\
Homa5 & $31 \pm 2$ & $119 \pm 6$ & $612 \pm 31$ \\
Homa6 & $216 \pm 17$ & $353 \pm 18$ & $766 \pm 38$ \\
Homa7 & $51 \pm 4$ & $331 \pm 17$ & $753 \pm 38$ \\
Homa8 & $45 \pm 4$ & $513 \pm 26$ & $1033 \pm 52$ \\
Homa9 & $157 \pm 13$ & $126 \pm 6$ & $789 \pm 39$ \\
Homa10 & $16 \pm 2$ & $84 \pm 4$ & $550 \pm 28$ \\
Homa11 & $223 \pm 18$ & $420 \pm 21$ & $991 \pm 50$ \\
Homa12 & $220 \pm 18$ & $417 \pm 21$ & $827 \pm 41$ \\
Homa13 & $78 \pm 6$ & $378 \pm 19$ & $964 \pm 48$ \\
Homa14 & $191 \pm 15$ & $479 \pm 24$ & $850 \pm 43$ \\
Homa15 & $72 \pm 6$ & $367 \pm 18$ & $889 \pm 44$ \\
Average & $129 \pm 10$ & $399 \pm 20$ & $894 \pm 45$ \\
\hline
\end{tabular}

TABLE 2: Activity concentration of ${ }^{40} \mathrm{~K},{ }^{226} \mathrm{Ra}$, and ${ }^{232} \mathrm{Th}(\mathrm{Bq} / \mathrm{kg})$ in Ruri samples.

\begin{tabular}{lccc}
\hline Sample ID & ${ }^{226} \mathrm{Ra}(\mathrm{Bq} / \mathrm{kg})$ & ${ }^{232} \mathrm{Th}(\mathrm{Bq} / \mathrm{kg})$ & \\
\hline Ruri1 & $92 \pm 5$ & $1190 \pm 60$ & $580 \pm 29$ \\
Ruri2 & $103 \pm 5$ & $1843 \pm 92$ & $451 \pm 23$ \\
Ruri3 & $81 \pm 4$ & $724 \pm 36$ & $526 \pm 26$ \\
Ruri4 & $21 \pm 2$ & $403 \pm 20$ & $333 \pm 17$ \\
Ruri5 & $63 \pm 3$ & $2152 \pm 108$ & $320 \pm 16$ \\
Ruri6 & $71 \pm 4$ & $1550 \pm 78$ & $742 \pm 37$ \\
Ruri7 & $110 \pm 6$ & $1486 \pm 74$ & $739 \pm 37$ \\
Ruri8 & $226 \pm 11$ & $1058 \pm 53$ & $487 \pm 24$ \\
Ruri9 & $145 \pm 7$ & $896 \pm 45$ & $566 \pm 28$ \\
Ruri10 & $189 \pm 9$ & $929 \pm 46$ & $306 \pm 15$ \\
Ruri11 & $46 \pm 2$ & $873 \pm 44$ & $156 \pm 8$ \\
Ruri12 & $87 \pm 4$ & $1236 \pm 62$ & $731 \pm 37$ \\
Ruri13 & $196 \pm 10$ & $1201 \pm 60$ & $812 \pm 41$ \\
Ruri14 & $174 \pm 9$ & $580 \pm 29$ & $358 \pm 18$ \\
Ruri15 & $68 \pm 3$ & $298 \pm 15$ & $221 \pm 11$ \\
Average & $111 \pm 6$ & $1094 \pm 55$ & $489 \pm 24$ \\
\hline
\end{tabular}

nearly equal to the mean value in Ruri [1]. Radium equivalent $\left(\mathrm{Ra}_{\mathrm{eq}}\right)$ for ${ }^{226} \mathrm{Ra},{ }^{232} \mathrm{Th}$, and ${ }^{40} \mathrm{~K}$ and the total radium equivalent in Homa and Ruri are presented in $\mathrm{Ta}-$ bles 3 and 4, respectively. The average radium equivalents for ${ }^{226} \mathrm{Ra}$ were more or less the same in both regions given their nearly equal activity concentrations. $\mathrm{Ra}_{\mathrm{eq}}$ for ${ }^{232} \mathrm{Th}$ was $60 \%$ higher in Ruri which had an average of $1564 \pm 125 \mathrm{~Bq} / \mathrm{kg}$, while ${ }^{40} \mathrm{~K}$ in Homa was higher by a factor of 2 relative to Ruri which was $38 \pm 3 \mathrm{~Bq} / \mathrm{kg}$.

Figures 2 and 3 show pie chart representation of the contribution of ${ }^{226} \mathrm{Ra},{ }^{232} \mathrm{Th}$, and ${ }^{40} \mathrm{~K}$ to total $\mathrm{Ra}_{\text {eq }}$ in Homa and Ruri, respectively. In Homa hill, ${ }^{232} \mathrm{Th}$ contributed $74 \%$ as ${ }^{40} \mathrm{~K}$ contributed $9 \%$ to total $\mathrm{Ra}_{\text {eq }}$ despite ${ }^{40} \mathrm{~K}$ having the highest activity concentration, while in Ruri, ${ }^{232} \mathrm{Th}$ contributed $91 \%$ to total $\mathrm{Ra}_{\text {eq }}$, the lowest contributor still being ${ }^{40} \mathrm{~K}$ at just $2 \%$ of total $\mathrm{Ra}_{\mathrm{eq}} \cdot{ }^{232} \mathrm{Th}$ was therefore the highest contributor to the total radium equivalent and radiation exposure in both regions. The determined average total radium equivalent in Homa was $767 \pm 61 \mathrm{~Bq} / \mathrm{kg}$ which was just $40 \%$ of the total average radium equivalent in Ruri.
The indoor annual effective dose rate $(D)$ is determined from the absorbed gamma radiation dose rates in Tables 3 and 4 for Homa and Ruri, respectively, using equation (4). The average annual effective dose rate in Homa and Ruri was $338 \pm 30 \mathrm{nGy} / \mathrm{h}$ and $733 \pm 66 \mathrm{nGy} / \mathrm{h}$, respectively, both of which were above the world average of $84 \mathrm{nGy} / \mathrm{h}$ [19]. The average annual effective dose rate in Homa was $1.74 \pm 0.14 \mathrm{mSv} / \mathrm{y}$ which was about half that of Ruri. Figure 4 shows a bar graph presentation of the percentage contribution of ${ }^{226} \mathrm{Ra},{ }^{232} \mathrm{Th}$, and ${ }^{40} \mathrm{~K}$ to the total annual effective dose rate. ${ }^{232} \mathrm{Th}$ contributed the highest percentage of about $65 \%$ and $85 \%$ to the indoor annual effective dose in Homa and Ruri, respectively, compared to ${ }^{40} \mathrm{~K}$ and ${ }^{226} \mathrm{Ra} .{ }^{40} \mathrm{~K}$ contributed the least to the effective dose in both regions despite it having a high activity concentration. Approximately $80 \%$ of the sampled points in Homa had indoor AEDR above the recommended safety limit of $1 \mathrm{mSv} / \mathrm{y}$, while all the sampled points in Ruri were above this limit [19].

The results obtained in this work have been compared with results reported in building materials in other high 
TABLE 3: Radium equivalent $\left(\mathrm{Ra}_{\mathrm{eq}}\right)$, absorbed gamma radiation dose rate $(D)$, and indoor annual effective dose rate (AEDR) in Homa.

\begin{tabular}{lcccccc}
\hline Sample ID & ${ }^{226} \mathrm{Ra} \mathrm{Ra}_{\mathrm{eq}}\left(A_{\mathrm{Ra}}\right)$ & ${ }^{232} \mathrm{Th} \mathrm{Ra}_{\mathrm{eq}}\left(1.429 \mathrm{~A}_{\mathrm{Th}}\right)$ & ${ }^{40} \mathrm{~K} \mathrm{Ra}_{\mathrm{eq}}\left(0.0769 A_{\mathrm{k}}\right)$ & $\mathrm{Ra}_{\mathrm{eq}}($ total $)(\mathrm{Bg} / \mathrm{kg})$ & $D(\mathrm{nGy} / \mathrm{h})$ & Indoor AEDR $(\mathrm{mSv} / \mathrm{y})$ \\
\hline Homa1 & $259 \pm 21$ & $855 \pm 68$ & $73 \pm 6$ & $1186 \pm 95$ & $520 \pm 47$ & $2.68 \pm 0.21$ \\
Homa2 & $178 \pm 14$ & $957 \pm 80$ & $100 \pm 8$ & $1235 \pm 99$ & $541 \pm 49$ & $2.79 \pm 0.22$ \\
Homa3 & $67 \pm 5$ & $704 \pm 63$ & $80 \pm 6$ & $851 \pm 68$ & $372 \pm 33$ & $1.92 \pm 0.15$ \\
Homa4 & $129 \pm 10$ & $902 \pm 71$ & $85 \pm 7$ & $1116 \pm 89$ & $487 \pm 44$ & $2.51 \pm 0.20$ \\
Homa5 & $31 \pm 2$ & $170 \pm 49$ & $47 \pm 4$ & $248 \pm 20$ & $112 \pm 10$ & $0.58 \pm 0.05$ \\
Homa6 & $216 \pm 17$ & $504 \pm 53$ & $59 \pm 5$ & $779 \pm 62$ & $345 \pm 31$ & $1.78 \pm 0.14$ \\
Homa7 & $51 \pm 4$ & $473 \pm 51$ & $58 \pm 5$ & $582 \pm 47$ & $255 \pm 23$ & $1.31 \pm 0.11$ \\
Homa8 & $45 \pm 4$ & $733 \pm 63$ & $79 \pm 6$ & $858 \pm 69$ & $374 \pm 34$ & $1.93 \pm 0.15$ \\
Homa9 & $157 \pm 13$ & $180 \pm 56$ & $61 \pm 5$ & $398 \pm 32$ & $182 \pm 16$ & $0.94 \pm 0.07$ \\
Homa10 & $16 \pm 1$ & $120 \pm 3$ & $42 \pm 3$ & $178 \pm 14$ & $81 \pm 7$ & $0.42 \pm 0.03$ \\
Homa11 & $223 \pm 18$ & $600 \pm 60$ & $76 \pm 6$ & $899 \pm 72$ & $398 \pm 36$ & $2.05 \pm 0.16$ \\
Homa12 & $220 \pm 18$ & $596 \pm 57$ & $64 \pm 5$ & $879 \pm 70$ & $388 \pm 35$ & $2.00 \pm 0.16$ \\
Homa13 & $78 \pm 6$ & $540 \pm 68$ & $74 \pm 6$ & $692 \pm 55$ & $305 \pm 27$ & $1.57 \pm 0.13$ \\
Homa14 & $191 \pm 15$ & $684 \pm 59$ & $65 \pm 5$ & $941 \pm 75$ & $413 \pm 37$ & $2.13 \pm 0.17$ \\
Homa15 & $72 \pm 6$ & $524 \pm 57$ & $68 \pm 5$ & $665 \pm 53$ & $292 \pm 26$ & $1.50 \pm 0.12$ \\
Average & $129 \pm 10$ & $570 \pm 46$ & $69 \pm 5$ & $767 \pm 61$ & $338 \pm 30$ & $1.74 \pm 0.14$ \\
\hline
\end{tabular}

TABLE 4: Radium equivalent $\left(\mathrm{Ra}_{\mathrm{eq}}\right)$, absorbed gamma radiation dose rate $(D)$, and indoor annual effective dose rate (AEDR) in Ruri.

\begin{tabular}{lcccccc}
\hline Sample ID & ${ }^{226} \mathrm{Ra} \mathrm{Ra}_{\mathrm{eq}}\left(A_{\mathrm{Ra}}\right)$ & ${ }^{232} \mathrm{Th} \mathrm{Ra}_{\mathrm{eq}}\left(1.429 \mathrm{~A}_{\mathrm{Th}}\right)$ & ${ }^{40} \mathrm{~K} \mathrm{Ra}_{\mathrm{eq}}\left(0.0769 A_{\mathrm{k}}\right)$ & $\mathrm{Ra}_{\mathrm{eq}}(\mathrm{Total})(\mathrm{Bg} / \mathrm{kg})$ & $D(\mathrm{nGy} / \mathrm{h})$ & Indoor AEDR $(\mathrm{mSv} / \mathrm{y})$ \\
\hline Ruri1 & $92 \pm 7$ & $1701 \pm 136$ & $45 \pm 4$ & $1837 \pm 147$ & $221 \pm 20$ & $1.14 \pm 0.09$ \\
Ruri2 & $103 \pm 8$ & $2634 \pm 211$ & $35 \pm 3$ & $2771 \pm 222$ & $267 \pm 24$ & $1.38 \pm 0.11$ \\
Ruri3 & $81 \pm 6$ & $1035 \pm 83$ & $40 \pm 3$ & $1156 \pm 92$ & $446 \pm 40$ & $2.30 \pm 0.18$ \\
Ruri4 & $21 \pm 2$ & $576 \pm 46$ & $26 \pm 2$ & $622 \pm 50$ & $497 \pm 45$ & $2.56 \pm 0.20$ \\
Ruri5 & $63 \pm 5$ & $3075 \pm 246$ & $25 \pm 2$ & $3163 \pm 253$ & $555 \pm 50$ & $2.86 \pm 0.23$ \\
Ruri6 & $71 \pm 6$ & $2215 \pm 177$ & $57 \pm 5$ & $2343 \pm 187$ & $632 \pm 57$ & $3.26 \pm 0.26$ \\
Ruri7 & $110 \pm 9$ & $2123 \pm 170$ & $57 \pm 5$ & $2290 \pm 183$ & $661 \pm 60$ & $3.41 \pm 0.27$ \\
Ruri8 & $226 \pm 18$ & $1512 \pm 121$ & $37 \pm 3$ & $1775 \pm 142$ & $764 \pm 69$ & $3.94 \pm 0.31$ \\
Ruri9 & $145 \pm 12$ & $1280 \pm 102$ & $44 \pm 3$ & $1469 \pm 118$ & $785 \pm 71$ & $4.05 \pm 0.32$ \\
Ruri10 & $189 \pm 15$ & $1328 \pm 106$ & $24 \pm 2$ & $1540 \pm 123$ & $817 \pm 74$ & $4.21 \pm 0.34$ \\
Ruri11 & $46 \pm 4$ & $1248 \pm 100$ & $12 \pm 1$ & $1306 \pm 104$ & $850 \pm 76$ & $4.38 \pm 0.35$ \\
Ruri12 & $87 \pm 7$ & $1766 \pm 141$ & $56 \pm 4$ & $1909 \pm 153$ & $979 \pm 88$ & $5.05 \pm 0.40$ \\
Ruri13 & $196 \pm 16$ & $1716 \pm 137$ & $62 \pm 5$ & $1975 \pm 158$ & $1000 \pm 90$ & $5.15 \pm 0.41$ \\
Ruri14 & $174 \pm 14$ & $829 \pm 66$ & $28 \pm 2$ & $1030 \pm 82$ & $1180 \pm 106$ & $6.08 \pm 0.49$ \\
Ruri15 & $68 \pm 5$ & $426 \pm 34$ & $17 \pm 1$ & $511 \pm 41$ & $1342 \pm 121$ & $6.92 \pm 0.55$ \\
Average & $111 \pm 09$ & $1564 \pm 125$ & $38 \pm 3$ & $1713 \pm 137$ & $733 \pm 66$ & $3.78 \pm 0.30$ \\
\hline
\end{tabular}

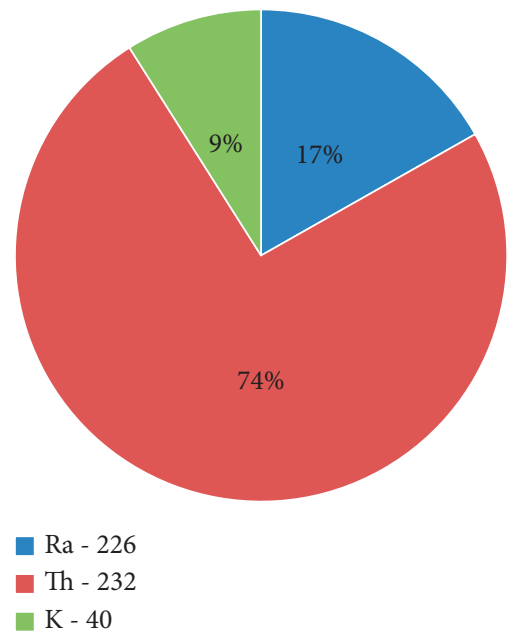

Figure 2: Percentage contributions of ${ }^{226} \mathrm{Ra},{ }^{232} \mathrm{Th}$, and ${ }^{40} \mathrm{~K}$ to total $\mathrm{Ra}_{\text {eq }}$ in the 15 samples from Homa area analyzed in this work. 


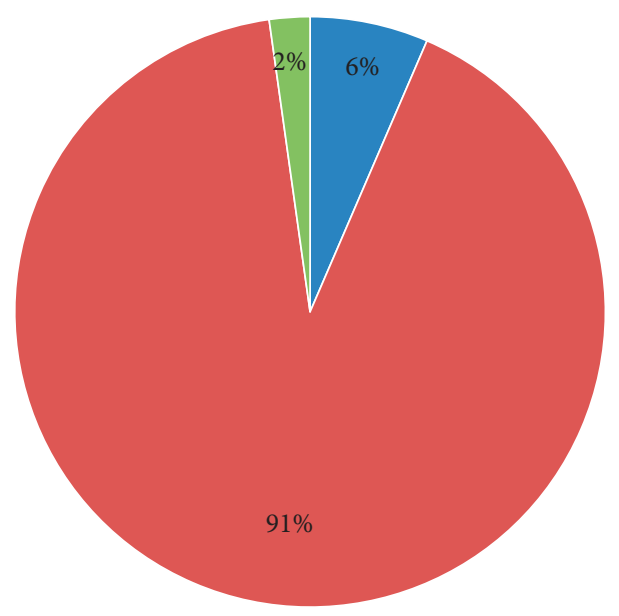

- $\mathrm{Ra}-226$

- Th - 232

K - 40

Figure 3: Percentage contributions of ${ }^{226} \mathrm{Ra},{ }^{232} \mathrm{Th}$, and ${ }^{40} \mathrm{~K}$ to total $\mathrm{Ra}_{\mathrm{eq}}$ in the 15 samples from Ruri area analyzed in this work.

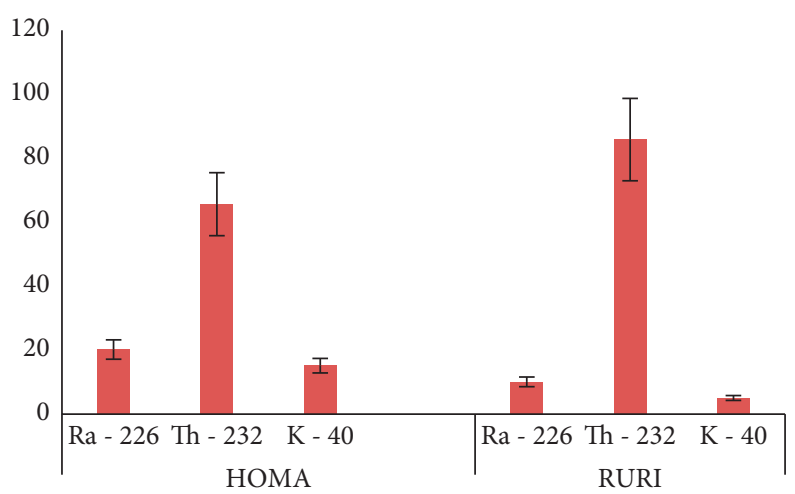

FIgURE 4: Percentage contribution of ${ }^{226} \mathrm{Ra},{ }^{232} \mathrm{Th}$, and ${ }^{40} \mathrm{~K}$ to the indoor annual effective dose rate.

TABLE 5: Comparison of the average activity concentrations of ${ }^{226} \mathrm{Ra},{ }^{232} \mathrm{Th}$, and ${ }^{40} \mathrm{~K}, \mathrm{Ra}_{\mathrm{eq}}$, and AEDR in Homa, Ruri, and other HBRA regions in Kenya and others around the world.

\begin{tabular}{lccccccr}
\hline Region & Country & \multicolumn{3}{c}{$\begin{array}{c}\text { Activity concentration } \\
(\mathrm{Bq} / \mathrm{kg}){ }^{226} \mathrm{Ra}\end{array}$} & $\mathrm{Ra}_{\mathrm{eq}}$ (total) $(\mathrm{Bq} / \mathrm{kg}){ }^{232} \mathrm{Th}$ & AEDR (mSv/y) ${ }^{40} \mathrm{~K}$ & Reference \\
\hline Homa & Kenya & 129 & 399 & 894 & 767 & 1.7 & 3.9 \\
Ruri & Kenya & 111 & 1094 & 489 & 1713 & 1.8 & This work \\
Mrima & Kenya & 134 & 431 & 249 & - & - & This work \\
Ramsar & Iran & 179 & 29 & 202 & 144 & {$[8]$} \\
Nile Delta & Egypt & 107 & 201 & 116 & 404.8 & {$[11]$} \\
Kanyakumari & India & 31 & 206 & 1590 & 437 & {$[20]$} \\
\hline
\end{tabular}

background radiation areas in Kenya and others around the world as tabulated in Table $5[8,11,20,21] .{ }^{40} \mathrm{~K}$ was $70 \%$ and $50 \%$ higher in Homa and Ruri, respectively, compared to Mrima hill, Kenya. On the contrary, ${ }^{232}$ Th was $60 \%$ higher in Ruri compared to Mrima which attributed to monazite and pyrochlore minerals in Ruri which contains higher thorium levels [1].

\section{Conclusion}

The levels of activity concentration of ${ }^{226} \mathrm{Ra},{ }^{232} \mathrm{Th}$, and ${ }^{40} \mathrm{~K}$ in earthen building materials used in high background radiation areas of Homa and Ruri have been assessed using the $\mathrm{NaI}(\mathrm{Tl})$ detector. The average concentration of ${ }^{226} \mathrm{Ra},{ }^{232} \mathrm{Th}$, and ${ }^{40} \mathrm{~K}$ was above the world average values of $35 \mathrm{~Bq} / \mathrm{kg}$, 
$30 \mathrm{~Bq} / \mathrm{kg}$, and $400 \mathrm{~Bq} / \mathrm{kg}$, respectively [1]. The radium equivalent, absorbed gamma radiation dose rate, and indoor annual effective dose rate have also been determined from the measured activity concentrations. ${ }^{232} \mathrm{Th}$ was the highest contributor to the total radium equivalent and indoor annual effective dose rates in both Homa and Ruri; it is therefore the radionuclide responsible for the largest radiation exposure in the two regions attributed to high monazite levels associated with high ${ }^{232} \mathrm{Th}$ levels. The determined average indoor annual effective dose rates were all above the recommended safety limit of $1 \mathrm{mSv} / \mathrm{y}$ in both Homa and Ruri [19]. Therefore, the earthen building materials in both hills are not safe for the construction of the dwellings.

\section{Data Availability}

The data used to support the findings of this study are available from the corresponding author upon request.

\section{Conflicts of Interest}

The authors declare that they have no conflicts of interest.

\section{Acknowledgments}

The authors would like to thank the National Commission for Science, Technology and Innovation (NACOSTI) for the research permit they granted them.

\section{References}

[1] D. Annex and United Nations, "Scientific committee on the effects of atomic radiation," Investigation of, vol. 1, p. 125, 2000.

[2] A. M. El-Arabi, G. E. Adel, A. G. E. Abbady, and H. I. Khalif, "Geochemistry and radioactive characteristics of the garnetiferous granite of um-sleimat area, Egypt," Journal of Earth Sciences, vol. 1, pp. 9-20, 2007.

[3] M. Sowmya, B. Senthilkumar, B. R. R. Seshan et al., "Natural radioactivity and associated dose rates in soil samples from Kalpakkam, South India," Radiation Protection Dosimetry, vol. 141, no. 3, pp. 239-247, 2010.

[4] Y. Yuan and H. Shen, "Recent advances of dosimetry investigation in the high background radiation area in Yangjiang, China," Chinese Journal of Radiological Medicine and Protection, vol. 15, no. 5, pp. 311-316, 1995.

[5] D. C. Vasconcelos, P. A. Reis, C. Pereira, A. H. Oliveira, T. O. Santos, and Z. Rocha, "Modelling natural radioactivity in sand beaches of guarapari," 2013.

[6] M. Ghiassi-Nejad, S. M. J. Mortazavi, J. R. Cameron, A. Niroomand-Rad, and P. A. Karam, "Very high background radiation areas of Ramsar, Iran: preliminary biological studies," Health Physics, vol. 82, no. 1, pp. 87-93, 2002.

[7] E. P. Christa, P. J. Jojo, V. K. Vaidyan, S. Anilkumar, and K. P. Eappen, "Radiation dose in the high background radiation area in Kerala, India," Radiation Protection Dosimetry, vol. 148, no. 4, pp. 482-486, 2012.

[8] M. W. Chege, Modelling radon and thoron exhalation and measurement of total natural radiation exposure in mrima hill, Kenya, Ph.D. Thesis, Kenyatta University, Nairobi, Kenya, 2015.
[9] D. Otwoma, J. P. Patel, S. Bartilol, and A. O. Mustapha, "Estimation of annual effective dose and radiation hazards due to natural radionuclides in mount Homa, southwestern Kenya," Radiation Protection Dosimetry, vol. 155, no. 4, pp. 497-504, 2013.

[10] S. O. Achola, J. P. Patel, A. O. Mustapha, and H. K. Angeyo, "Natural radioactivity and external dose in the high background radiation area of Lambwe East,Southwestern Kenya," Radiation Protection Dosimetry, vol. 152, no. 4, pp. 423-428, 2012.

[11] E. Bavarnegin, M. Moghaddam, and N. Fathabadi, "Natural radionuclide and radiological assessment of building materials in high background radiation areas of Ramsar, Iran," Journal of Medical Physics, vol. 38, no. 2, p. 93, 2013.

[12] M. J. Le Bas, "Carbonatite-nephelinite volcanism: an African case history," Wiley, UK, London, 1977.

[13] G. J. H. McCall, "Geology of the gwasi area: geol," Survey Kenya, Rept, vol. 45, p. 88, 1958.

[14] M. Tzortzis, H. Tsertos, S. Christofides, and G. Christodoulides, "Gamma-ray measurements of naturally occurring radioactive samples from Cyprus characteristic geological rocks," Radiation Measurements, vol. 37, no. 3, pp. 221-229, 2003.

[15] J. Beretka and P. J. Mathew, "Natural radioactivity of Australian building materials, industrial wastes and by-products," Health Physics, vol. 48, no. 1, pp. 87-95, 1985.

[16] United Nations Scientific Committee on The Effects of Atomic Radiation, Sources of Ionizing Radiation, United Nations Scientific committee on Effects of Atomic Radiation, Report, New York, NY, USA, 1993.

[17] P. A. Colgan, C. Organo, C. Hone, and D. Fenton, "Radiation doses received by the irish population," 2008.

[18] G. N. Mayaka, N. O. Hashim, and H. K. Angeyo, "Measurement of radon activity concentration in waters from homa mountain south western Kenya," International Journal of Science, Enviroment and Technology, vol. 4, pp. 2278-7798, 2015.

[19] International Commission on Radiological Protection (ICRP), Low-Dose Extrapolation of Radiation related cancer risks, ICRP Publication, Oxford, UK, 2005.

[20] F. Mubarak, M. Fayez-Hassan, N. A. Mansour, T. S. Ahmed, and A. Ali, "Radiological investigation of high background radiation areas Nile Delta, Egypt," Scientific Reports, vol. 7, no. 1, pp. 1-12, 2017.

[21] G. Shanthi, J. Thampi Thanka Kumaran, G. Allen Gnana Raj, and C. G. Maniyan, "Measurement of activity concentration of natural radionuclides for the assessment of radiological indices," Radiation Protection Dosimetry, vol. 141, no. 1, pp. 90-96, 2010. 